\title{
Evaluasi Layanan Teknologi Informasi ITIL Versi 3 Domain Service Design pada Universitas Selamat Sri Kendal
}

Didin Herlinudinkhaji ${ }^{1}$

${ }^{1}$ Universitas Selamat Sri Kendal

\begin{abstract}
Information technology is a necessity for companies and organizations. To ensure the continuity of information technology business processes, it is also very necessary that companies get added value for their use. ITIL v3 is a method used to designing, ensure value is met, provide quality services, and ensure that the parts run as desired. Service design is used to assist companies in designing infrastructure, architecture, service quality, policies, and documents IT. ITIL v3 domain service design in this study is also used as a basis for developing information technology usage policies. To evaluate this information technology service using a questionnaire method to the ITIL V3 domain service design consist of 7 items. The results of this study indicate that by $57 \%$ there needs to be a total improvement in services and $43 \%$ are good enough in serving customers.
\end{abstract}

Keyword : Service Design, Information Technology Infrastructure Library, ITIL V3, Infrastructure Information Technology.

\begin{abstract}
Abstrak
Teknologi informasi sudah menjadi kebutuhan utama bagi perusahaan ataupun organisasi. Untuk menjamin keberlangsungan proses bisnis teknologi informasi juga sangat diperlukan agar perusahaan mendapatkan nilai tambah terhadap penggunaannya. ITIL v3 merupakan salah satu alat yang digunakan untuk merancang, mendesain, memastikan nilai terpenuhi, memberikan pelayanan berkualitas, serta memastikan bagian-bagian tersebut berjalan sesuai dengan yang diinginkan. Service design digunakan untuk membantu perusahaan dalam mendesain infrastruktur, arsitektur, kualitas layanan, kebijakan, serta dokumen layanan teknologi informasi. ITIL v3 domain service design pada penelitian ini juga digunakan sebagai dasar untuk pengembilan kebijakan penggunaan teknologi informasi. Untuk melakukan evaluasi layanan teknologi informasi ini dengan menggunakan metode kuesioner yang disesuaikan dengan framework ITIL V3 domain service design yang terdiri dari 7 item. Hasil dari penelitian ini menunjukkan bahwa sebesar $57 \%$ perlu adanya perbaikan total terhadap layanan dan $43 \%$ sudah cukup baik dalam melayani pelanggan.

Kata Kunci : $\quad$ Sercive Design, ITIL V3, Manajemen Layanan Teknologi Informasi, Layanan Infrastruktur Teknologi Informasi, Desain Layanan TI.
\end{abstract}

ISSN 2715-0143 (online) ISSN 2714-9048 (print)

http://journal.walisongo.ac.id/index.php/jit/index 


\section{PENDAHULUAN}

Manajemen Layanan Teknologi Informasi banyak digunakan untuk keperluan mengelola layanan terhadap teknologi informasi. Layanan teknologi informasi menjadi penting dalam kegiatan manajemen bidang teknologi informasi terutama untuk keperluan audit dalam layanan tersebut (herlinudinkhaji, 2015). Audit terhadap layanan teknologi informasi tersebut digunakan untuk mengetahui sejauh mana penggunaan layanan teknologi informasi dapat menjadi jembatan untuk perkembangan terhadap bisnis suatu perusahaan. Sehingga manajemen terhadap layanan menjadi lebih penting untuk mengelola layanan teknologi informasi yang perubahan terhadap layanan tersebut sewaktuwaktu dapat berubah menyesuaikan kebutuhan (wang, 2013).

Teknologi informasi sudah menjadi bagian dari kebutuhan dalam bidang pendidikan, kesehatan, pemerintahan, hiburan, bisnis dan sebagainya, bahkan sekarang teknologi informasi sudah menjadi kebutuhan utama jika melihat kebutuhan smartphone saat ini. Bisnis membutuhkan teknologi informasi sebagai kebutuhan utamanya, akibatnya resiko dari kaemanan sistem, keamanan informasi, dan keamanan infrastrukturnya menjadi barang mahal (feng dkk, 2013). Hal ini menunjukkan bahwa untuk mendukung pelaksanaan teknologi informasi maka diperlukan strategi dalam penggunaan teknologi informasi untuk meningkatkan kualitas layanan teknologi informasi. Tata kelola terhadap layanan teknologi informasi dapat meningkatkan kualitas layanan, dapat mengurangi risiko, meningkatkan kinerja terhadap nilai, dan mengurangi biaya layanan teknologi informasi (Jogiyanto dan Abdillah, 2011).

Teknologi informasi dapat merubah nilai bisnis menjadi lebih tinggi jika dalam pengelolaannya disesuaikan dengan standar yang sudah diterapkan secara internasional salah satu contohnya yaitu Information Technology Infrastructrure Library (ITIL) versi 3. ITIL merupakan best practice yang berstandar internasional yang dapat membantu dalam melakukan penerapan teknologi informasi pada organisasi atau perusahaan menjadi nilai tambah bagi perusahaan atau organisasi. Tata kelola teknologi informasi menjadi sangat penting untuk dapat mengelola setiap aktivitas perusahaan, diantaranya strategi dan kebijakan terhadap infrastruktur perusahaan atau organisai, juga bisa mengelola layanan teknologi informasi dengan lebih baik.

Universitas Selamat Sri (UNISS) Kendal merupakan salah satu perguruan tinggi swasta baru di Kabupaten Kendal yang mulai operasionalnya sejak tahun 2016. Untuk dapat mengelola kebutuhannya terutama pada bidang teknologi informasi maka diperlukan adanya suatu metode ataupun cara agar pengelolaan teknologi informasi dapat memberikan nilai tambah terhadap organisasi. Pada bagian awal 
UNISS perlu merancang pengelolaan teknologi informasi agar layanan terhadap sivitas akademika berjalan dengan baik. ITIL versi 3 merupakan best practice yang dapat membantu berjalannya bisnis dan mendukung perusahaan untuk mencapai tujuan atau goal yang diinginkan. ITIL versi 3 terdiri dari lima domain, diantara yaitu Service Strategy, Service Design, Service Transition, Service Operation, Continual Service Improvement (OGC, 2007). Masing-masing domain memiliki peranan yang berbeda-beda. Pada penelitian ini penelliti menitikberatkan pada domain Service Design yang berfungsi untuk melakukan perubahan dengan mendesain infrastruktur Teknologi Informasi, kualitas layanan Teknologi Informasi, melakukan kebijakan terhadap keamanan Teknologi Informasi, dan melakukan pengukuran terhadap layanan.

\section{METODE}

\subsection{Bahan dan Alat Penelitian}

Bahan yang digunakan dalam penelitian ini adalah sebagai berikut :

a. Studi literatur

Langkah awal yang dilakukan yaitu dengan mencari bahan literatur berupa jurnal maupun buku best practice yang berkaitan dengan ITIL versi 3. Penulis juga mengumpulkan data dan informasi yang berkaitan dengan pemanfaatan metode ITIL versi 3 yang bersumber pada jurnal penelitian nasional maupun internasional, dan ditunjang juga buku ITIL versi 3. b. Survey kuesioner

Kuesioner disebarkan kepada pengelola perusahaan atau organisasi untuk mendapatkan data sesuai dengan apa yang diharapkan. Data kuesioner ini berupa data mentah yang kemudian diolah. Data kuesioner ini pembuatannya berdasarkan ITIL domain service design yang terdiri atas service catalogue management, service level management, availability management, IT service continuity management, information security menegement, and supplier management. Proses-proses tersebut dibuat dengan tujuan untuk mengetahui desain yang digunakan untuk layanan TI yang meliputi arsitektur TI, proses, kebijakan, serta dokumentasi yang digunakan untuk memenuhi kebutuhan sekarang dan pada masa yang akan datang. Pengolahan data ini menggunakan uji validitas dan uji reabilitas.

Uji validitas digunakan untuk mengetahui seberapa aktual data yang akan digunakan dengan nyata atau benar. Pengukuran ini juga menentukan valid atau tidaknya data. Pengukuran dikatakan tidak valid jika pengukurannya menyimpang dari tujuannya (Jogiyanto, 2011).

Uji reabilitas digunakan untuk mengetahui seberapa akurat data tersebut dapat diandalkan (Jogiyanto, 2011). Pengukuran yang dikatakan reliabel adalah pengukuran yang dapat dipercaya. Pengukuran yang dapat dipercaya adalah pengukuran yang akurat dan konsisten (jogiyanto, 2011) terhadap beberapa subjek yang sama dan diperoleh hasil yang tidak berbeda. 


\begin{tabular}{|c|c|c|c|c|c|c|c|c|c|}
\hline & & 1 & 2 & 3 & 4 & 5 & 6 & 7 & Total \\
\hline & 1 & 1 & & & & & & & \\
\hline & 2 & 0 & 1 & & & & & & \\
\hline & 3 & 0.28868 & 0.70833 & 1 & & & & & \\
\hline & 4 & 0.28868 & 0.41667 & 0.70833 & 1 & & & & \\
\hline & 5 & 0.42857 & 0.28868 & 0.28868 & 0 & 1 & & & \\
\hline & 6 & 0.14907 & 0.34427 & 0.34427 & 0.34427 & 0.14907 & 1 & & \\
\hline & 7 & 1 & 0 & 0.28868 & 0.28868 & 0.42857 & 0.14907 & 1 & \\
\hline Total & & 0.6957 & 0.60249 & 0.7942 & 0.6664 & 0.56921 & 0.5374 & 0.6957 & 1 \\
\hline & & $\begin{array}{l}0.49731 \\
\text { valid }\end{array}$ & $\begin{array}{l}0.49731 \\
\text { valid }\end{array}$ & $\begin{array}{c}0.49731 \\
\text { valid }\end{array}$ & $\begin{array}{l}0.49731 \\
\text { valid }\end{array}$ & $\begin{array}{c}0.49731 \\
\text { valid }\end{array}$ & $\begin{array}{c}0.49731 \\
\text { valid }\end{array}$ & $\begin{array}{c}0.49731 \\
\text { valid }\end{array}$ & \\
\hline \multicolumn{10}{|c|}{ Gambar 1} \\
\hline
\end{tabular}

\begin{tabular}{r|l|l}
\hline \multicolumn{3}{c}{ Reliability Statistics } \\
\hline Cronbach's Alpha & $\begin{array}{l}\text { Cronbach's } \\
\text { Alpha Based on } \\
\text { Standardized } \\
\text { Items }\end{array}$ & N of Items \\
\hline & .775 & \multicolumn{774}{c}{} & \\
\hline & & 7 \\
\hline
\end{tabular}

Gambar 2

Hasil Uji Reliabilitas

\section{c. Observasi}

Observasi ini dilakukan dengan mengamati infrastruktur teknologi informasi yang mencakup software, hardware, maupun brainware. Dari pendukung fisik maupun non fisik yang berkaitan dengan infrastruktur penulis amati. Data ini masih berupa data mentah yang kemudian diolah dengan menggunakan excel.

Selain bahan penelitian juga terdapat alat yang digunakan untuk melakukan penelitian ini, adapun alat yang digunakan dalam penelitian ini adalah sebagai berikut :

a. Perangkat keras
Perangkat keras ini digunakan untuk mengelola dan analisis data yang berasal dari bahan penelitian dengan spesifikasi sebagai berikut:

- Prosesor minimal speed $2.00 \mathrm{GHz}$

- RAM minimal $1 \mathrm{~GB}$

- Hardisk minimal free space $1 \mathrm{~GB}$

b. Perangkat lunak

Perangkat lunak yang digunakan untuk mengelola dan analisis data berupa sistem operasi baik linux mapun windows, perangkat spreedsheet, perangkat lunak olah data (SPSS maupun excel).

c. Akses internet 
Evaluasi Layanan Teknologi Informasi ITIL Versi 3 Domain Service Design pada Universitas Selamat Sri Kendal

Kebutuhan untuk dapat mengakses internet digunakan untuk mencari studi literatur baik berupa jurnal (nasional maupun internasional), framework ITIL v3, dan buku tentang ITIL v3 domain service design.

\subsection{Prosedur Penelitian}

Prosedur penelitian ditunjukkan pada gambar 3.

\section{KERANGKA TEORI}

\subsection{ITSM (Information Technology Service Managemnt)}

Information Technology Service Management (ITSM) merupakan salah satu metode best pracrice untuk mengelola teknologi informasi yang berfokus pada layanan kepada pelanggan (Iden dan Eikebrokk, 2013). Semua layanan yang diberikan kepada pelanggan dikelola dengan baik menggunakan teknologi informasi. Pelanggan diberikan fasilitas berupa kenyamanan, kemudahan, keamanan, dan kepercayaan melakukan transaksi terhadap proses bisnis melalui teknologi informasi. Beberapa manfaat yang didapatkan dalam mengelola bisnis dengan ITSM adalah sebagai berikut : (1) mutu pelayanan dapat meningkat, (2) pelanggan merasa dihormati dengan memberikan kebebasan kepada pelanggan untuk memberikan masukan dan langsung ditanggapi, (4) proses bisnis yang dijalankan terpusat sehingga dapat dikontrol dengan baik, (5) tingkat kepercayaan pelanggan tinggi sehingga dapat meningkatkan produktifitas bisnis, dan (6) meningkatkan keuntungan.

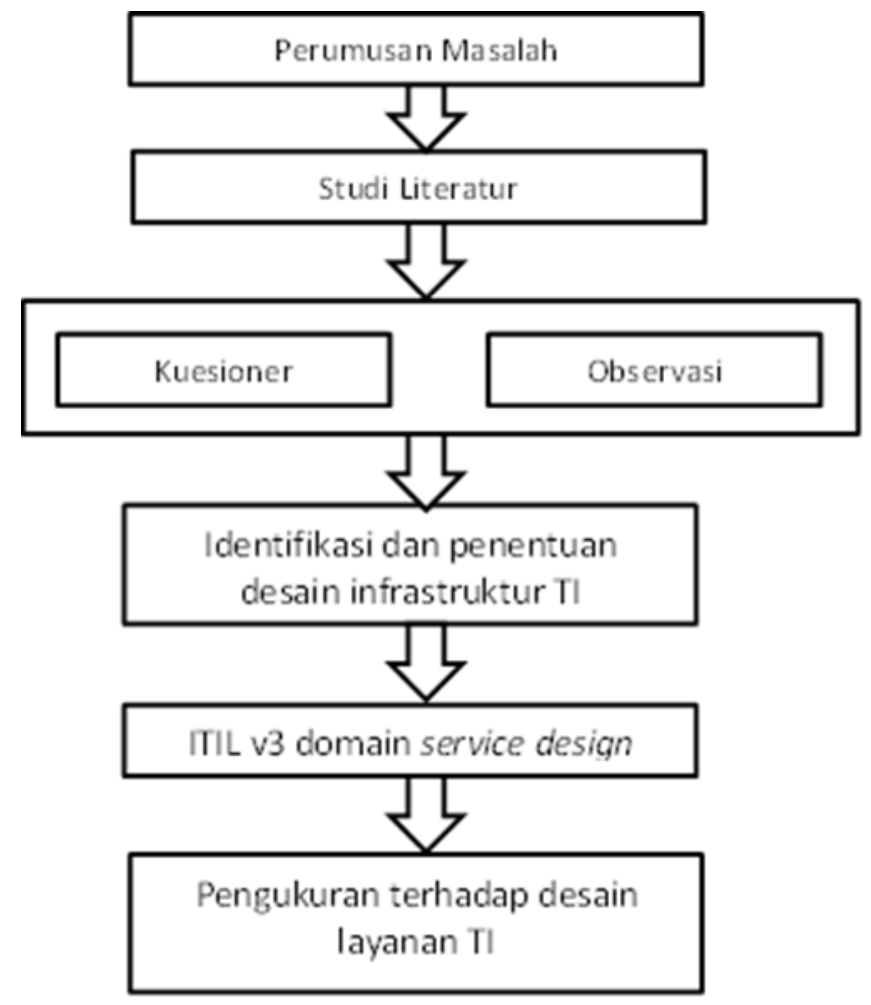




\section{Gambar 3}

Prosedur penelitian

3.2. ITIL (Information Technologi Infrastructure Library)

Awal mulaa ITIL diterbitkan antara tahun 1989 dan 1995 oleh Her Majesty's Stationery Office (HMSO) di Inggris atas nama Central Communications and Telecommunications Agency (CCTA) sekarang CCTA dimasukan dalam Office of Government Commerce (OGC). Penggunaan awal pada ITIL terbatas di Inggris dan Belanda. Versi kedua ITIL diterbitkan sebagai suatu set revisi buku antara tahun 2000 dan
2004. ITIL versi 3 mulai diperbaiki dan ditingkat pada tahun 2007, terdiri dari lima buku inti yang mencakup siklus hidup layanan (service lifecycle), bersama-sama dengan Official Introduction. Kelima buku tersebut meliputi Service Strategy, Service Design, Service Transition, Service Operation, dan Continual Service Improvement (OGC, 2007).

Dari lima domain tersebut dapat digambarkan dlam siklus hidup layanan ITIL yang ditunjukkan oleh gambar 4.

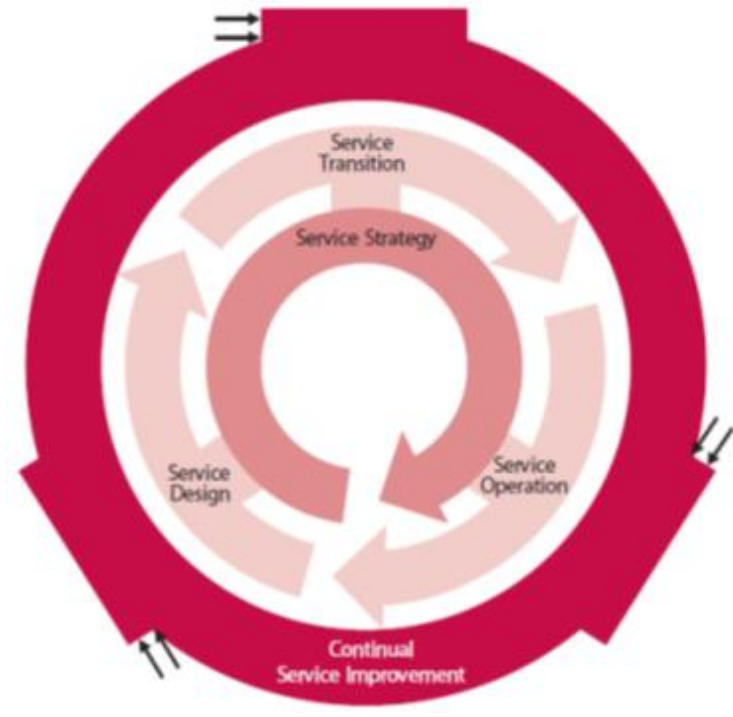

Gambar 4

Siklus hidup layanan ITIL (OGC, 2007)

Siklus hidup layanan teknologi informasi dengan ITIL v3 diawali dari strategi layanan yang berfungsi untuk menganalisisa kebutuhan terhadap bisnis. Kemudian dilanjutkan ke desain layanan yang berfungsi untuk melakukan perubahan terhadap pola bisnis dengan mendesain infrastruktur, kualitas layanan, kebijakan terhadap keamanan layanan, dan melakukan pengukuran terhdap layanan teknologi informasi. Transisi layanan merupakan langkah berikutnya setelah melakukan desain terhadap layanan. Pada tahapan ini fokusnya adalah memberikan layanan terbaik terhadap semua layanan dan memberikan nilai tambah terhadap 
layanan. Setelah pelanggan mendapatkan laynan terbaik maka pada tahap selanjutnya adalah operasi layanan. Pada bagian ini pelanggan dapat memastikan bahwa trasaksi yang sudah dilakukan akan diterima dan disampaikan dengan baik. Tahapan yang terakhir yaitu melakukan evalusi terhadap kualitas layanan dan memastikan bahwa pada bagian-bagian tersebut sudah berjalan sesuai dengan fungsinya masingmasing.

\subsection{ITIL v3 domain Service Design}

ITIL domain service design yang terdiri atas (1) service catalogue management, (2) service level management, (3) capacity management, (4) availability management, (5) IT service continuity management, (6) information security menegement, and (7) supplier management. Desain layanan merupakan salah satu tahapan dalam siklus hidup layanan ITIL secara keseluruhan.

Tujuan dan sasaran utama desain layanan adalah (1) proses ini memastikan bahwa dapat memberikan manfaat terhadap bisnis yang sudah disepakati, (2) prsose yang dilakukan dapat menunjang terhadap siklus hidup layanan, (3) dapat mengidentifikasi serta mengelola terhadap risiko bisnis, (4) membangun infrastruktur TI yang aman, lingkungan layanan TI nyaman, arsitektur TI, kebijakan terhadap layanan, serta dokuman yang tersimpan dengan baik sehinga dapat menjadi solusi untuk kualitas layanan $\mathrm{TI}$, (5) menempatkan sumber dayanya sesuai dengan kemampuan dan keahliannya, (6) semua elemen saling berkontribusi terhadap pengingkatan kualitas layanan TI.

Dalam prosesnya desain layanan tergantung terhadap empat elemen penting yang dikelompokkan dalam P.

> People: orang-orang, keahlian dan kemampuan yang terlibat dalam penyediaan layanan TI

> Product: teknologi dan sistem manajemen yang digunakan dalam memberikan layanan TI

> Processes: proses, peran dan aktifitas yang terlibat dalam penyediaan layanan TI

> Partners: vendor, perusahaan dan penyedia yang digunakan untuk memberikan dan mendukung penyediaan layanan TI

\section{PEMBAHASAN}

\subsection{Instrumen Penelitian}

Berdasarkan hasil kuesioner yang didapatkan sesuai dengan ITIL v3 domain service design diperoleh pernyataan yang terdapat dalam kuesioner :

Tabel 1

Pernyataan dalam desain layanan

\begin{tabular}{llc}
\hline \multicolumn{2}{c}{ Pernyataan } & Jumlah pernyataan \\
\hline 1 & Manajemen terhadap katalog layanan & 7 \\
2 & Tingkat layanan terhadap pelanggan & 4 \\
3 & Kesesuaian bisnis atau kapasitas manajemen & 5 \\
4 & Manajemen ketersediaan layanan serta dukungan & 9 \\
5 & organisasi & 5 \\
\hline
\end{tabular}


Didin Herlinudinkhaji ${ }^{1}$

6 Keberlangsungan layanan TI 7

7 Pengelolaan terhadap keamanan informasi 6

Pengelolaan terhadap penyedia atau supplier

4.2. Hasil kuesioner

Tabel 2

Validitas pernyataan

\begin{tabular}{|c|c|c|c|c|}
\hline Pernyataan & Item & $r$ hitung & $r$ tabel & Keterangan \\
\hline \multirow{7}{*}{$\begin{array}{c}\text { Manajemen } \\
\text { terhadap katalog } \\
\text { layanan }\end{array}$} & $\mathrm{AO1}$ & 0,693 & 0,497 & Valid \\
\hline & $\mathrm{AO} 2$ & 0,601 & 0,497 & Valid \\
\hline & $\mathrm{AO3}$ & 0,801 & 0,497 & Valid \\
\hline & $\mathrm{AO4}$ & 0,667 & 0,497 & Valid \\
\hline & $\mathrm{AO5}$ & 0,561 & 0,497 & Valid \\
\hline & AO6 & 0,517 & 0,497 & Valid \\
\hline & $\mathrm{AO7}$ & 0,534 & 0,497 & Valid \\
\hline \multirow{4}{*}{$\begin{array}{c}\text { Tingkat layanan } \\
\text { terhadap } \\
\text { pelanggan }\end{array}$} & BL1 & 0,581 & 0,497 & Valid \\
\hline & BL2 & 0,511 & 0,497 & Valid \\
\hline & BL3 & 0,533 & 0,497 & Valid \\
\hline & BL4 & 0,645 & 0,497 & Valid \\
\hline \multirow{5}{*}{$\begin{array}{c}\text { Kesesuaian } \\
\text { bisnis atau } \\
\text { kapasitas } \\
\text { manajemen }\end{array}$} & $\mathrm{C} 1$ & 0,921 & 0,497 & Valid \\
\hline & $\mathrm{C} 2$ & 0,655 & 0,497 & Valid \\
\hline & C3 & 0,549 & 0,497 & Valid \\
\hline & $\mathrm{C} 4$ & 0,553 & 0,497 & Valid \\
\hline & $\mathrm{C} 5$ & 0,571 & 0,497 & Valid \\
\hline \multirow{9}{*}{$\begin{array}{l}\text { Manajemen } \\
\text { ketersediaan } \\
\text { layanan serta } \\
\text { dukungan } \\
\text { organisasi }\end{array}$} & D1 & 0,519 & 0,497 & Valid \\
\hline & D2 & 0,668 & 0,497 & Valid \\
\hline & D3 & 0,668 & 0,497 & Valid \\
\hline & D4 & 0,517 & 0,497 & Valid \\
\hline & D5 & 0,638 & 0,497 & Valid \\
\hline & D6 & 0,519 & 0,497 & Valid \\
\hline & D7 & 0,623 & 0,497 & Valid \\
\hline & D8 & 0,623 & 0,497 & Valid \\
\hline & D9 & 0,668 & 0,497 & Valid \\
\hline \multirow{5}{*}{$\begin{array}{l}\text { Keberlangsungan } \\
\text { layanan TI }\end{array}$} & E1 & 0,608 & 0,497 & Valid \\
\hline & E2 & 0,565 & 0,497 & Valid \\
\hline & E3 & 0,675 & 0,497 & Valid \\
\hline & E4 & 0,733 & 0,497 & Valid \\
\hline & E5 & 0,733 & 0,497 & Valid \\
\hline \multirow{2}{*}{$\begin{array}{l}\text { Pengelolaan } \\
\text { terhadap }\end{array}$} & F1 & 0,614 & 0,497 & Valid \\
\hline & $\mathrm{F} 2$ & 0,542 & 0,497 & Valid \\
\hline
\end{tabular}


Evaluasi Layanan Teknologi Informasi ITIL Versi 3 Domain Service Design pada Universitas Selamat Sri Kendal

\begin{tabular}{ccccc}
\hline Pernyataan & Item & r hitung & r tabel & Keterangan \\
\hline keamanan & F3 & 0,550 & 0,497 & Valid \\
informasi & F4 & 0,925 & 0,497 & Valid \\
& F5 & 0,614 & 0,497 & Valid \\
& F6 & 0,602 & 0,497 & Valid \\
& F7 & 0,602 & 0,497 & Valid \\
\hline Pengelolaan & G1 & 0,775 & 0,497 & Valid \\
terhadap & G2 & 0,775 & 0,497 & Valid \\
penyedia atau & G3 & 0,528 & 0,497 & Valid \\
supplier & G4 & 0,733 & 0,497 & Valid \\
& G5 & 0,575 & 0,497 & Valid \\
& G6 & 0,575 & 0,497 & Valid \\
\hline
\end{tabular}

Dari tabel 2 dapat ditunjukkan tingkat validitas dari pernyataan yang menunjukkan bahwa sudah valid pernyataan tersebut.

Tabel 3

Hasil reliabilitas pernyataan

\begin{tabular}{c|l|c|c}
\hline item & \multicolumn{1}{|c|}{ Variabel } & $\begin{array}{c}\text { Cronbach's } \\
\text { Alpha }\end{array}$ & r tabel \\
\hline A & Manajemen terhadap katalog layanan & 0,775 & 0,497 \\
\hline B & Tingkat layanan terhadap pelanggan & 0,647 & 0,497 \\
\hline C & Kesesuaian bisnis atau kapasitas manajemen & 0,662 & 0,497 \\
\hline D & $\begin{array}{l}\text { Manajemen ketersediaan layanan serta } \\
\text { dukungan organisasi }\end{array}$ & 0,794 & 0,497 \\
\hline E & Keberlangsungan layanan TI & 0,566 & 0,497 \\
\hline F & Pengelolaan terhadap keamanan informasi & 0,705 & 0,497 \\
\hline G & Pengelolaan terhadap penyedia atau supplier & 0,721 & 0,497 \\
\hline
\end{tabular}

Tabel 4

Hasil dari pengujian dan Evaluasi 


\begin{tabular}{|c|c|c|c|c|c|c|c|}
\hline \multirow{3}{*}{ item } & \multicolumn{5}{|c|}{ Tanggapan responden } & \multirow{2}{*}{ SKOR } & \multirow[b]{2}{*}{ KATEGORI } \\
\hline & SB (5) & B (4) & $C(3)$ & KB (2) & SK (1) & & \\
\hline & $\%$ & $\%$ & $\%$ & $\%$ & $\%$ & & \\
\hline A & 0,00 & 2,31 & 3,08 & 15,38 & 2,31 & 67 & SANGAT TIDAK BAIK \\
\hline $\mathrm{B}$ & 1,54 & 3,85 & 7,69 & 7,69 & 2,31 & 83 & BIASA \\
\hline $\mathrm{C}$ & 0,00 & 2,31 & 3,85 & 15,38 & 1,54 & 69 & SANGAT TIDAK BAIK \\
\hline $\mathrm{D}$ & 0,00 & 3,85 & 11,54 & 6,15 & 1,54 & 83 & \begin{tabular}{|c|} 
BIASA \\
\end{tabular} \\
\hline$E$ & 0,00 & 2,31 & 7,69 & 7,69 & 5,38 & 69 & SANGAT TIDAK BAIK \\
\hline $\mathrm{F}$ & 0,00 & 0,00 & 3,85 & 15,38 & 3,85 & 60 & SANGAT TIDAK BAIK \\
\hline $\mathrm{G}$ & 0,00 & 3,85 & 7,69 & 7,69 & 3,85 & 75 & BIASA \\
\hline
\end{tabular}

\subsection{Hasil pengujian dan Evaluasi}

Berdasarkan hasil data kuesioner dapat diambil kesimpulan dengan memperhatikan pada tabel 4.

Berdasarkan framework ITIL V3 domain service design yang terdiri dari 7 item diantaranya (a) Manajemen terhadap katalog layanan; (b) Tingkat layanan terhadap pelanggan; (c) Kesesuaian bisnis atau kapasitas manajemen; (d) Manajemen ketersediaan layanan serta dukungan organisasi;

(e) Keberlangsungan layanan TI; (f) Pengelolaan terhadap keamanan informasi; (g) Pengelolaan terhadap penyedia atau supplier.

Dari ke-7 item tersebuttTerdapat empat item yang perlu diperbaiki yaitu tentang manajemen terhadap katalog, keseuaian bisnis atau kapasitas manajemen, keberlangsungan layanan $\mathrm{TI}$, serta pengelolaan terhadap keamanan informasi.

Terdapat tiga item yang penilaianya dianggap cukup atau biasa yaitu tentang tingkat layanan terhadap pelanggan, manajemen ketersediaan layanan serta dukungan organisasi, dan pengelolaan terhadap penyedia atau supplier.

\section{PENUTUP}

Berdasarkan penelitian ini dengan menggunakan ITIL V3 domain service design dapat diambil kesimpulan bahwa evaluasi kepada pelanggan akan menghasilkan kategori berupa sangat baik (skor > 120), baik (skor 96 - 120), biasa (skor 72 - 95), tidak baik (skor 48 - 71), dan sangat tidak baik (skor < 48).

Berdasarkan tabel 4 di atas dapat disimpulkan bahwa untuk kategori Sangat Tidak Baik sebesar $57 \%$ dan Biasa atau Cukup sebesar $43 \%$. Hal ini menunjukkan bahwa pengelolaan teknologi informasi pada Universitas Selamat Sri (UNISS) belum sesuai dengan ITIL V3 domain service design. Desain awal pada saat penggunaan teknologi informasi untuk tata kelola infrastruktur teknologi informasi, arsitektur, kualitas layanan, kebijakan serta dokumen belum dilakukan secara maksimal.

1. Untuk menentukan kebijakan penggunaan teknologi informasi 
Evaluasi Layanan Teknologi Informasi ITIL Versi 3 Domain Service Design pada Universitas Selamat Sri Kendal

perlu dilakukan pengkajian terhadap permasalahan yang terjadi

2. ITIL v3 domain service design merupakan salah satu alat yang dapat digunakan untuk membantu organisasi atau perusahaan untuk melakukan desain infrastruktur dalam penggunaan teknologi informasi
3. Hasil dari penelitian ini menunjukkan bahwa masih ada beberapa kekurangan terutama jika penerapan teknologi informasi berbasis daring dan perlu adanya perkembangan lebih lanjut terkait penggunaan daring. 


\section{DAFTAR PUSTAKA}

Bernroider, Edward W.N., dan Ivanov, Milen. (2010), IT Project management control and the Control Objectives for IT and Technology (CobiT) framework, International Journal of Project Management, 29, 325-336.

Chang, Hangbae. (2012), Is ISMS for financial organizations effective on their business?, Mathematical and Computer Modelling, 212.

Herlinudinkhaji, Didin (2015), Audit Layanan Teknologi Informasi berbasis Information Technology Infrastructure Library (ITIL), Jurnal Informatika UPGRIS, 01(02), $12-15$

Huang. Shi-Ming, \& Shen, Wei-Cheng, Yen, \& David, C., Chou, Ling-Yi. (2011), IT Governance : Objectives and assurances in internet banking, Journal Advance in International Acounting, 27, 406-414.

IBISA, (2011), Keamanan Sistem Informasi, Yogyakarta, ANDI Offset.

Iden, J, dan Eikebrokk, T.T. (2013), Implementing IT Service Management: A systematic literature review, International Journal of Information Management, 33, 512- 523.

Jogiyanto, 2008, Metodologi Penelitian Sistem Informasi, ANDI Offset, Yogyakarta.

Jogiyanto, 2011, Pedoman Survey Kuesioner, BPFE, Yogyakarta.

Jogiyanto dan Abdillah, Willy, (2011), Sistem Tata Kelola Teknologi Informasi, Yogyakarta, ANDI Offset.

Julisch, Klaus, Suter, Christophe, Woitalla, Thomas, Zimmermann, Olaf, (2011), Compliance By Design Bridging The Chasm Between Auditors And IT Architects, Computer and Security, 30, 410-426.

McNaughton, Blake, Ray, Pradeep, dan Lewis, Lundy. (2010), Designing an evaluation framework for IT service management, Information and Management, 47, 219 -225.

Mesquida, Antoni, Lluís, Mas, Antonia, Amengual, Esperança, Manzano, Calvo, Jose, A. (2012), IT Service Management Process Improvement based on ISO/IEC 15504: A systematic review, Information and Software Technology, 54, 239-247.

Nan, Feng, Wang, Jiannan, Harry, Li, Minqiang. (2013), A security risk analysis model for information systems : Causal relationships of risk factors and vulnerability propagation analysis, Information Sciences $\mathrm{xxx}$, xxx-xxx.

OGC, (2007), The Official Introduction to the ITIL Service Lifecycle, London, TSO.

OGC, (2007), Service Design, London, TSO.

Sarno, Riyanarto dan Tiffano, Irsyat. (2009), Sistem Manajemen Keamanan Informasi berbasis ISO 27001, ITS Press, Surabaya.

Stantchev, Vladimir, Petruch, Konstantin, dan Tamm, Gerrit, (2013), Assessing and governing IT-staff behavior by performance-based simulation, Computers in Human Behavior, 29, 473-485.

Susilowati. Susi. (2012), Evaluasi Tata Kelola Layanan Teknologi Informasi Pada Area Service Operation Menggunakan Kerangka Kerja ITIL Versi 3, Paradigma, (12), 09-12.

Wardani. Kusuma LA. \& Murahartawaty. Ramadhani Luthfi, (2016), Perancangan Tata Kelola Layanan Teknologi Informasi Menggunakan ITIL versi 3 Domain Service Transition dan Service Operation di Pemerintah Kota Bandung, Journal of Information System Enginerering and Business Intelligence, 2 (02), 10-16. 